\title{
A STUDY TO INVESTIQTATE THE HELP AND EDUCATION REQUIRED BY FAMILIES OF ELDERLY DISABLE闻 PEOPLE $\dagger$
}

\author{
C. DENTON*
}

The author set out to investigate the help and education required by families of elderly disabled people, in order to provide the best possible care for their elderly relatives.

Five families were used in the study. The size of the family unit ranged from the nuclear family unit of two members to extended families of nine members. The elderly disabled people were of both sexes of all racial groups and were at least 60 years of age. The disability rendered the patient unable to carry out normal or ordinary functions. The author made five visits to each family over a period of four months. The family was interviewed during the initial visit, to enable the author to understand as fully as possible the family's problems. The subsequent visits involved the implementation of an education plan, including practical, emotional and educational help. The success of the programme was judged subjectively, being determined by the present coping abilities of the families and the number of problems which they thought still relevant.

Results showed that all the families were still experiencing various problems, of which the following were common to all five families.

\section{MOBILITY AND INDEPENDENCE}

The elderly person was not achieving full functional ability, leaving the family with an unnecessary burden and the elderly person with a feeling of inadequacy. Reasons for immobility were poor understanding by the family or insufficient information by health professionals on the capabilities of the elderly person.

\section{FAMILY'S UNDERSTANDING OF THE DISABILITY}

There was a limited understanding of the disability, its prognosis, limitations and effect on the patient. This was due to poor explanation by bealth professionals at the time of discharge or misunderstanding on the part of the family.

\section{UNACCEPTANCE OF DISABILITY}

The elderly persons were in varying stages of acceptance. There was a need to encourage and motivate these patients. Any improvement, no matter how small, must be emphasised. Once the elderly person has accepted the disability, he is ready to make full use of his abilities. Emotions and feelings associated with disability have to be overcome to ensure the success of a rehabilitative programme.

+ Abstract of project completed as course requirement.

* Final year B.Sc. (Physiotherapy) student at University of Cape Town.

Received 7 September 1982.

\section{COMMUNICATION}

There was poor interaction between members of each family and in most cases this was due to poor communication. The family often felt the elderly person was being difficult and demanding, whilst the patient was in fact anxious and frustrated.

\section{PHYSICAL HEALTH OF 'CARER'}

The 'carer' was the family member who had assumed the main responsibility for care of the patient. In four out of five families, the 'carer's' health was not $100 \%$, thus limiting his own physical capabilities. This emphasises the need for an alternate 'carer' either in the family or the community.

\section{FINANCIAL}

It is obvious that disability is not economically beneficial. All economic groups are affected. For the lower income groups it is usually a wage earner who forfeits his job in order to care for the elderly person. In higher income groups it was found that financial resources were presently adequate but. with inflation and high medical expenses, these resources would be dwindling. Grants and other financial aid are available, but the families had very little knowledge of how to obtain such aid.

\section{-INADEQUATE KNOWLEDGE OF SERVICES AVAILABLE}

Services for elderly disabled people in South Africa are very limited. However, those available are not fully utilised. Assistive devices, such as wheelchairs and commodes, are easily obtainable.

In conclusion, the problems arising from caring for an elderly disabled person at home are varied, and affect every aspect of life. These needs can be very well met in the homes of the patients by health professionals. In this study the author dealt with only a small percentage of the patient and family needs but even this had a positive effect on the family. The patients began to utilise their residual ability, which resulted in an increase in independence. The family had a better understanding of the disability and the quality of care improved. The success of the programme was determined by the degree of active involvement by the family, the amount of support and guidance offered by the author, the contribution and intervention by other members of the health team and the availability of facilities in the community. Co-ordination between members of the health team is essential; enabling them to come together and focus on the individual patient as a whole in terms of his total environment and total problem. Personal contact with the family is of immense value in patient care. We, as health professionals, must aim to keep people out of institutions and in their own homes, functioning at maximum independence and thereby keeping families together. 